\title{
XVII. On the cooling of cylinders in a stream of air
}

\author{
J. Alfred Hughes B.Sc. E Coy R.A.M.C.
}

To cite this article: J. Alfred Hughes B.Sc. E Coy R.A.M.C. (1916) XVII. On the cooling of cylinders in a stream of air , Philosophical Magazine Series 6, 31:182, 118-130, DOI: 10.1080/14786440208635482

To link to this article: http://dx.doi.org/10.1080/14786440208635482

$$
\text { 曲 Published online: } 08 \text { Apr } 2009 .
$$

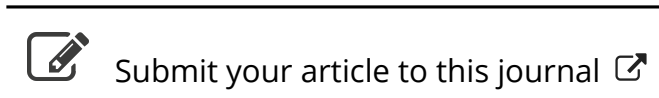

\section{Џll Article views: 8}

\section{Q View related articles $\square$}

Citing articles: 13 View citing articles 5 
On using the formula of Gauss

$$
\Psi(z)=\int_{0}^{\infty}\left\{\frac{e^{-t}}{t}-\frac{e^{-z t}}{1-e^{-t}}\right\} d t
$$

we get, without much difficulty,

$$
\begin{array}{r}
\pi \mathrm{T}_{n}=2 n\left[\log \left\{\lambda n \cot \left(\frac{1}{2} \lambda \pi\right)\right\}-\frac{1}{2} \psi(1-\lambda n)-\frac{1}{2} \psi(1+\lambda n)\right] \\
+\sum_{m=1} \frac{(-)^{m} \mathrm{~B}_{m}}{(2 m) !(2 n)^{2 m-1}}\left\{\psi^{(2 m-1)}\left(\frac{1}{2}-\frac{1}{2} \lambda\right)+\psi^{(2 m-1)}\left(\frac{1}{2}+\frac{1}{2} \lambda\right)\right. \\
\left.-\psi^{(2 m-1)}\left(1-\frac{1}{2} \lambda\right)-\psi^{(2 m-1)}\left(1+\frac{1}{2} \lambda\right)\right\},
\end{array}
$$

the remainder after $r$ terms having the same sign and being numerically less than the $(r+1)$ th term; where $\lambda$ is equal to $\beta /(2 \pi)$.

The corresponding series occurring in the transverse component of force is

$$
\begin{aligned}
\mathrm{U}_{n} & =\sum_{m=1}^{n-1} \cos \left(\frac{m \pi}{n}-\frac{1}{2} \beta\right) \operatorname{cosec}^{2}\left(\frac{m \pi}{n}-\frac{1}{2} \beta\right) \\
& =2 \frac{\partial \mathrm{T}_{n}}{\partial \beta}=\frac{1}{\pi} \frac{\partial \mathrm{T}_{n}}{\partial \lambda} ;
\end{aligned}
$$

this may be determined from the asymptotic expansion for $\mathrm{T}_{n}$, which may legitimately be differentiated term by term with respect to $\lambda$.

XVII. On the Cooling of Cylinders in a Stream of Air. By Pte. J. Alfred Hughes, B.Sc., E Coy, R.A.M.C., formerly Research Student, University College of North Wales, Bangor*.

$7 \mathrm{HE}$ interchange of heat between a solid and a moving 1 stream of gas is a subject of considerable technical importance, and also not devoid of scientific interest. A considerable amount of work has been done on the cooling of thin wires $\dagger$ in a current of air, mainly with the object of constructing instruments for the measurements of air-velocity. These experiments have shown that the heat lost by the wire is proportional to the difference of temperature and to the square-root of the velocity. There are, however, no data available relating to the convection of heat from bodies of large diameters; and the following experiments were undertaken with a view of throwing some light on the problem of convection in these cases.

* Communicated by Prof. E. Taylor Jones, D.Sc.

$\dagger$ King, Phil. Trans, 1914, p. 373. Morris, 'Electrician,' Oct. 4, 1912. 
Apparatus.

The measurements were carried out on a series of copper tubes all of the same length, but with external diameters ranging from $\cdot 433 \mathrm{~cm}$. to $5 \cdot 06 \mathrm{~cm}$. These tubes, of about a metre in length, were placed vertically in the wind-channel, and were heated by steam from a boiler placed on top of the channel; after a steady temperature was attained, the weight of the water which condensed in the cylinder in a given time measured the heat which it lost through convection and radiation.

The wind-channel, fig. 2, consisted of a wooden tunnel placed horizontally, which was of square section, of side 3 feet, and was 10 feet long. This terminated in a rectangular box of greater section in which the fan rotated.

The fan was made by attaching four narrow steel blades to the axle of a three-phase motor, the speed of which could be regulated (a) by a rotor rheostat, and (b) by varying the voltage of the alternator supplying the current. A good range of wind-velocity could thus be obtained. The velocity of the air currents produced by the fan was measured by the ordinary Pitot-tube and gauge. This consisted of two glass tubes of ${ }_{16}^{3}$ inch bore, the dynamic tube facing the wind, and the static tube being placed with the plane of its orifice parallel to the direction of the flow. T'hese tubes were placed close to. one another in the centre of the channel, immediately in front of the cooling cylinder. By means of rubber tubing they were connected to a water-gauge, the difference of level in which measured the difference of pressure, which was proportional to the square of the velocity as given by

$$
v=\sqrt{2 g h},
$$

$h$ being the pressure difference in metres of air, and $v$ the velocity in metres per second. The difference between the two sides of the U-tube was measured by a cathetometer microscope reading to $1 \frac{1}{0}$ of a millim. The gauge-tubes were $2 \mathrm{~cm}$. wide so as to avoid surface-tension errors. Large oscillations were produced in the liquid in the gauge on account of variation in the wind-pressure, and this caused a difficulty in measuring the wind-velocity. The oscillations were damped, and the amplitude reduced by loosely stopping the bottom of the U-tube with cotton-wool. In some of the later experiments, thick paraffin was adopted as the liquid in the gauge. With this, the difference of level was increased on account of the smaller density of the liquid, while the oscillations were reduced by reason of its greater viscosity. 
The Pitot-tube determined the wind-velocity at the middle of the channel; and since an average value of the velocity over the cylinder was required, a determination was made of how the wind-velocity varied along a vertical line through the position of the Pitot-tube. A reading was taken with the Pitot-tube in its ordinary position : then readings were taken for the same wind velocity at different points across the channel. Thus an average value was calculated for the channel, and this was done for different velocities of the wind. A graph was plotted (fig. 1) showing the relation between the Pitot-tube reading at the centre of the channel and the average reading tor the section. From this an average value can be read for any value of the axial wind-velocity.

Fig. 1.

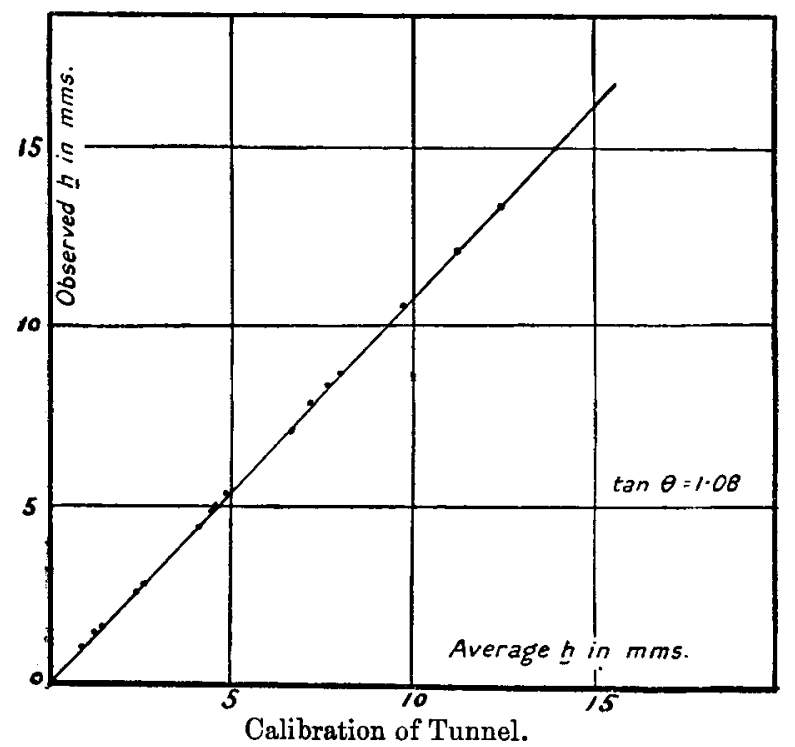

The heat lost was determined by finding the weight of water condensed. The arrangement of the steam generator is shown in fig. 2. The boiler A is placed on the top of the channel, and the steam passes into the top of the tube through the water-trap B placed directly over the tube. The whole was shielded from air-currents by an asbestos cover. With cylinders of the largest diameters and with the stream-line tubes, a metallic steam-trap covered with cotton-wool was used, and the tubes were soldered to the bottom of the can as shown in the diagram. 
The condensed water was collected in a beaker placed underneath the tubes, a glass funnel being attached to the bottom end of the copper tube to ensure that all the condensed water should be caught in the beaker; the excess of

Fig. 2.
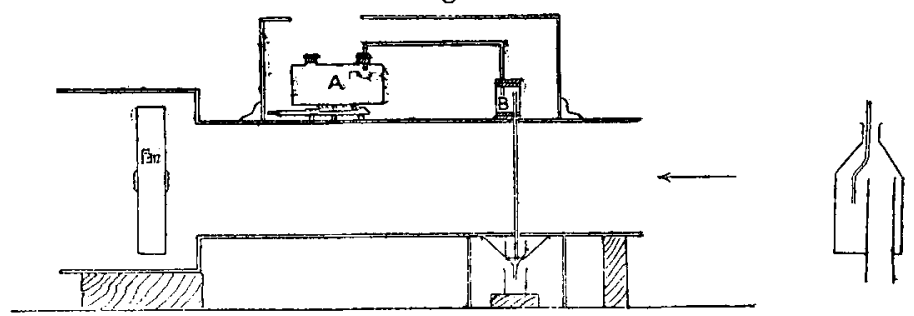

Fig. 3.

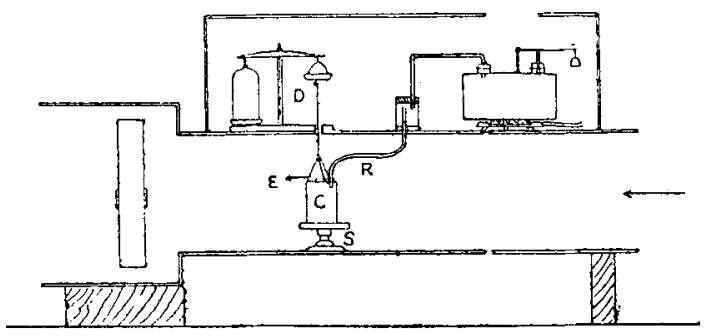

steam which came out with the condensed water escaped to the air past the sides of the tube. The end of the copper tube and the funnel were covered with cotton-wool. A wooden box was built round this receiving apparatus beneath the wind-channel, to shield it from air currents produced by the fan.

The experiment was carried on in the following manner. The water was boiled and the steam allowed to pass through the copper tube for about five minutes, to ensure that the steady temperature had been attained.

The first reading of the Pitot-tube was taken, the motor started, and after a short interval, a weighed beaker was placed underneath the end of the cylindrical tube, and the stop-watch started. Readings of the water "head" in the Pitot-tube gauge were registered, and after 10 minutes the beaker was taken away, and the motor stopped. The second zero of the gange was taken, and the beaker and water weighed. The temperature of the air and the atmospheric pressure were also taken.

Phil. Mag. S. 6. Vol. 31. No. 182. Feb.1916. K 
In the case of the Iarge cylinder, $20 \mathrm{~cm}$. length, $15.5 \mathrm{~cm}$. diameter, the arrangement of the apparatus is shown in fig. 3. The condensed water was allowed to collect in the cylinder Citself, the whole being suspended from a balance B placed on the top of the cliannel, the steam connexion being made by rubber-tubing $R$. When the balance-beam is down, the cylinder rests on a stand $\mathrm{S}$ in the channel; the excess of steam escapes through the exit $\mathrm{E}$.

The water condensed, which measures the heat lost, is estimated by taking the weight of the cylinder at the beginning and end of the interval of time, viz. 10 minutes. Steam is passed through for about 5 minutes, and after the steady temperature has been attained, the weight is taken and the motor started. After 10 minutes the motor is stopped and the weight again taken. The weight of the water condensed will be the sum of three parts: (1) that condensed by convection and radiation in still air in the interval from the first weighing till the motor was started; (2) the condensation during the wind-current; (3) the condensation in still air during the interval between the stopping of the motor and the time when the final weight is taken. The "water equivalent" of the excess of time above 10 minutes is found, and this subtracted from the total weight gives the weight of water condensed by the wind alone. Still-air condensation is small, as can be seen from Table II., and therefore no serious error is introduced by this method.

\section{Corrections.}

Most of the heat is lost from the cooling eylinders by convection, but some also by radiation. A correction can be applied for the heat lost by radiation, and this subtracted from the total loss of heat gives the heat lost by convection alone. The radiation correction was calculated from the equation

$$
\mathrm{R}=k\left(\theta^{4}-\theta_{0}^{4}\right) \text {, }
$$

where $R$ is the heat lost by radiation;

$k$ the coefficient of emissivity in gram-calories per sec. per sq. cm.;

$\theta-\theta_{0}$ the excess of temperature of the hot cooling body above the temperature of the surroundings.

$k^{*}$ was calculated from Bottomley's results to be $\cdot 63 \times 10^{-12}$ gm.-cals. per sec. per sq. cm. for tarnished copper;

* Phil. Traus. vol, clxxxiv. p. 591 (1893). 
Cooling of Cylinders in a Stream of Air.

and therefore $R$ per $\mathrm{cm}$. length

$$
=k \frac{\mathrm{A}}{l} t\left(\theta^{4}-\theta_{0}^{4}\right)
$$

$A=$ area in sq. cms.

$l=$ length in cms.

$t=$ time in secs.

The values obtained are given in Table I.

TABLE I.

\begin{tabular}{|c|c|}
\hline R (cals. per cm. length). & Diameter of Cylinder. \\
\hline 4 calories. & $-43 \mathrm{~cm}$. \\
$12.4 "$ & $81 "$ \\
$28.7 "$ & $1 \cdot 93 "$ \\
$75 "$ & $5 \cdot 06$, \\
234.3 & $15 \cdot 5, "$ \\
$113 "$ & Stream-line Section. \\
\hline
\end{tabular}

It has been assumed that the temperature of the outside surface of the cooling cylinder was the same as the temperature of the steam. This is practically true, as can be shown by calculating the value of $\theta_{2}-\theta_{1}$ from

$$
\left(\theta_{2}-\theta_{1}\right)=\frac{\mathrm{H} d}{2 \pi r k \mathrm{~T}},
$$

$\theta_{2}-\theta_{1}$ being the drop of temperature in the tube,

$\mathrm{H}$ the largest value of the heat which passes across the tube per cm. length in time $T$,

$r$ the mean radius $=15.4 \mathrm{~cm}$.,

$d$ the thickness $=\cdot 2 \mathrm{~cm}$.,

$k$ the conductivity of copper.

The value of $\theta_{2}-\theta_{1}$ is $03^{\circ} \mathrm{C}$, so that the temperature of the outside of cylinder can be taken to be $100^{\circ} \mathrm{C}$.

The quantity of water condensed depends on the density and the temperature of the air, so to obtain uniform results a correction was applied, and the quantity of water was reduced to a standard temperature and density.

\section{Results.}

Experiments were performed with five copper cylinders of diameters $\cdot 43, \cdot 81,1 \cdot 93,5 \cdot 06,15 \cdot 5 \mathrm{~cm}$. respectively, and the results obtained for the loss of heat in calories per $\mathrm{cm}$. length $(\mathrm{H})$ and the velocity (V) in metres per sec. are given in Table II. 


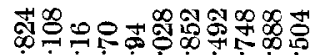

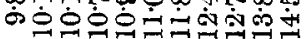

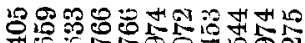

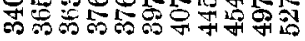

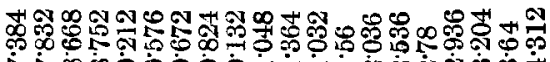
i-

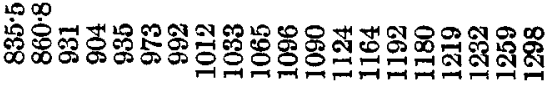

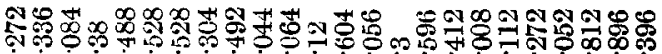

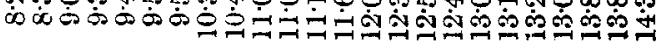

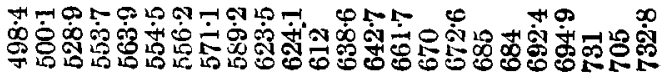

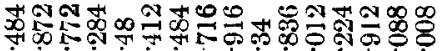

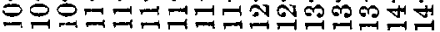

Q

एक

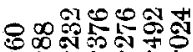

$\dot{\sigma} \dot{0} \dot{0} \dot{1} \dot{0}$

4.

is 
These are also shown in curves (fig. 4), the loss of heat having been plotted against the velocity.

Fig. 4.

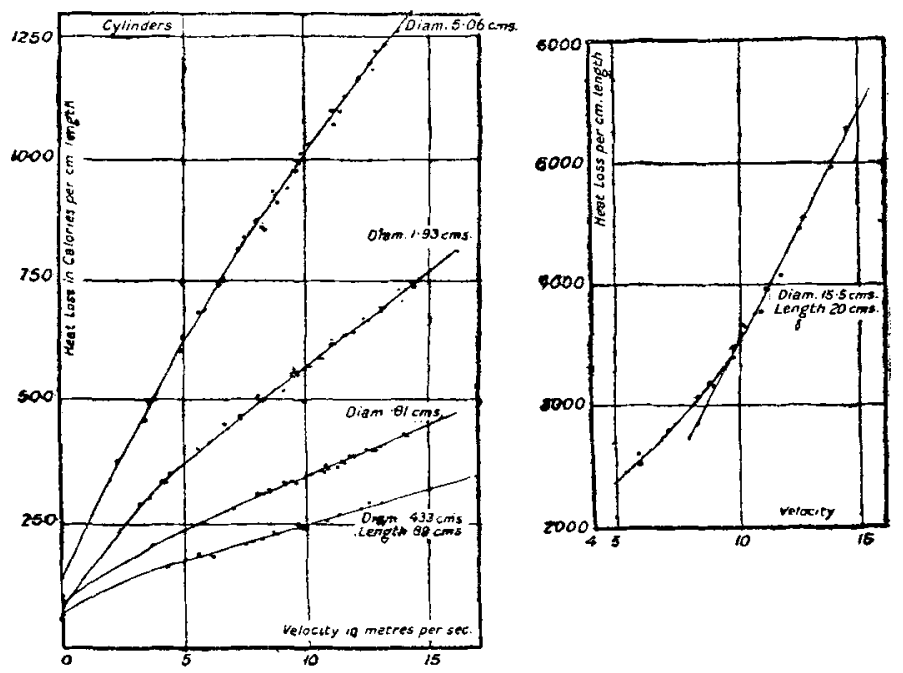

These curves show that the heat-loss is a function of the velocity which may approximately be represented by

$$
\mathrm{H}=k v^{n} \text {. }
$$

In order to find the index $n, \log \mathrm{H}$ is plotted against $\log V$, and a straight line drawn through the points. The inclination of this straight-line graph gives $n$.

The values of $n$ obtained for the various cylinders are exhibited in Table III.

TABLE III.

\begin{tabular}{|l|c|}
\hline \multicolumn{1}{|c|}{$n}$. & Diameter. \\
\hline .55 & $.43 \mathrm{~cm}$. \\
.6 & $.81 "$, \\
.65 & $1.93 "$ \\
.7 & $5.06 "$, \\
$.98,6$ at low velocities. & $15.5 \%$ \\
\hline
\end{tabular}

The above table shows that $n$ increases from $\cdot 5$ for cylinders of very small diameter to 1 for cylinders of large 
diameter, thus bringing into agreement the two formulæ which had boen obtained by different experimenters, $\mathrm{II}=k t v$ given by Reynolds, Nicholson, Williams for large bodies, while Boussinesq, Morris, King arrived at the formula $\mathrm{H}=k t v \vec{v}$ for wires. In the case of those cylinders, with which a number of readings at fairly low wind-velocities have been obtained, there are indications that the value of $n$ is much smaller. With the cylinder of diameter $1.93 \mathrm{~cm} ., n$ at very low velocities is $\cdot 57$, while at higher velocities $n$ is $\cdot 65$; and with the large cylinder of diameter $15.5 \mathrm{~cm} . n=\cdot 6$ at low wind-velocities, whereas at high velocities it is $\cdot 98$.

\section{Variation of Heat-Loss with Diameter.}

The way in which the heat lost varies with the diameter can be obtained by comparing the heat-loss from the different tubes at the same velocity. These values are plotted in fig. 5, and it will be seen that the heat lost is proportional to $d^{-57}$ at all velocities.

Fig. 5.

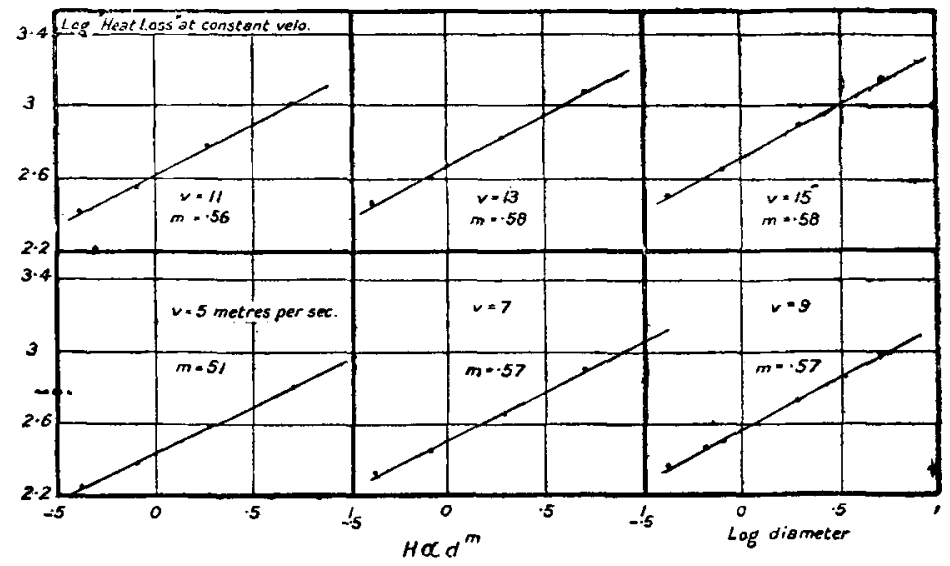

\section{Stream-Line Section.}

In several technical applications it is important that the cooling system should have as small an air resistance as possible, and accordingly a few experiments were made on a tube of stream-line section with the object of finding its efficiency for cooling purposes. The perimeter of the cross section of the tube was $23.1 \mathrm{~cm}$., its maximum thickness being $2 \mathrm{~cm}$. 
Experiments were performed with the tube placed thus

Direction of wind.

(1)

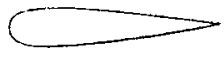

(2)

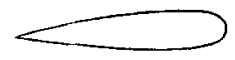

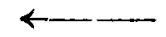

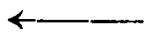

and a third set of readings was obtained with the tube in the second position, with a metallic strip, $\frac{1}{2}$ inch in width, placed in front. This was caused to oscillate by the wind and produced irregular convection. The results are given in Table IV., and they are aleo shown in curves in fig. 6 .

TABLE IV.

Loss of Heat $(\mathrm{H})$ and Velocity $(\mathrm{V})$ results for Stream-Line Tube. $\mathrm{H}=$ Calories per $\mathrm{cm}$. length. $\mathrm{V}=$ Velocity in metres per sec. $\mathrm{R}=$ Radiation corr. in cals. per cm. length $=113$.

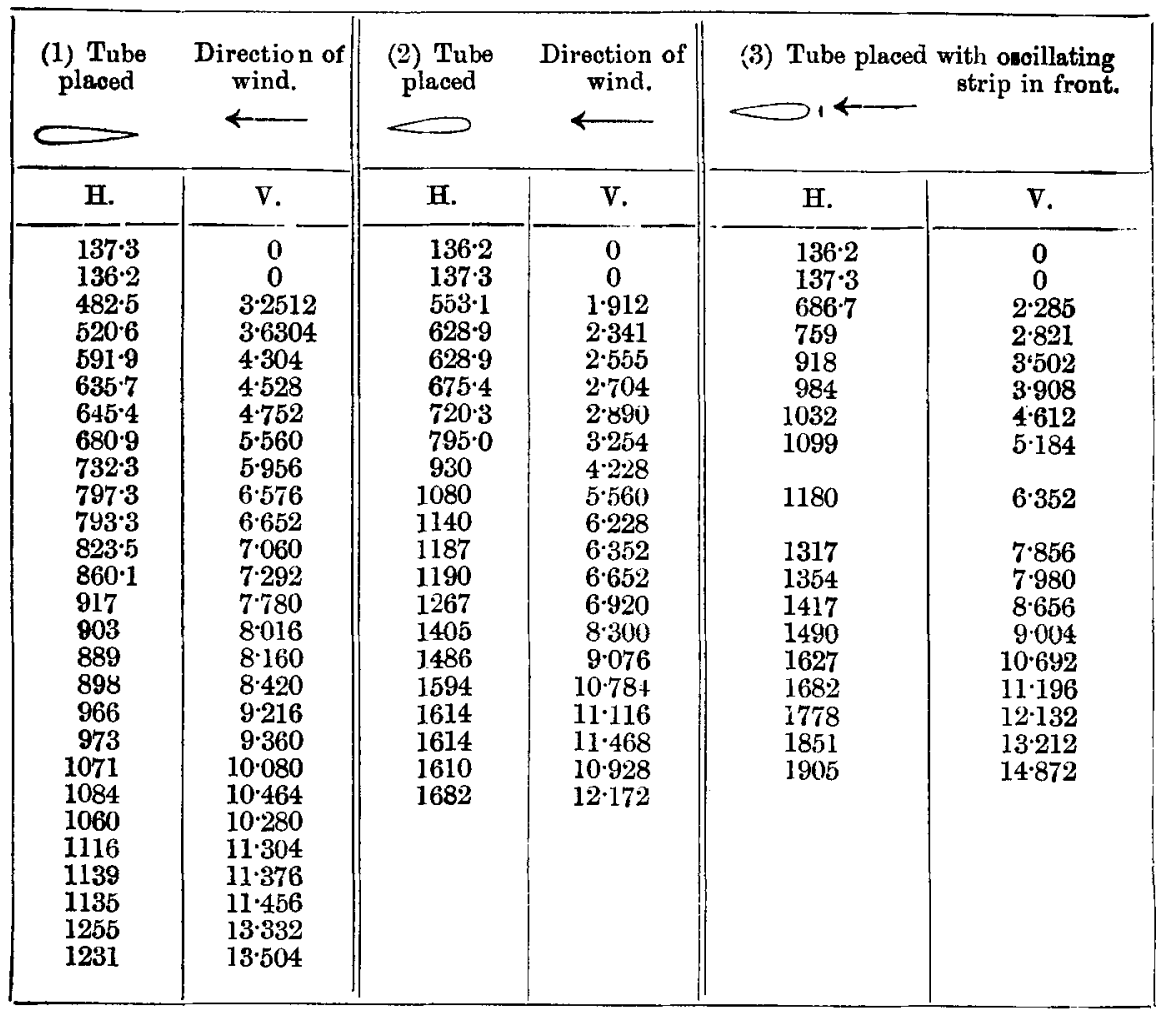


Fig. 6.

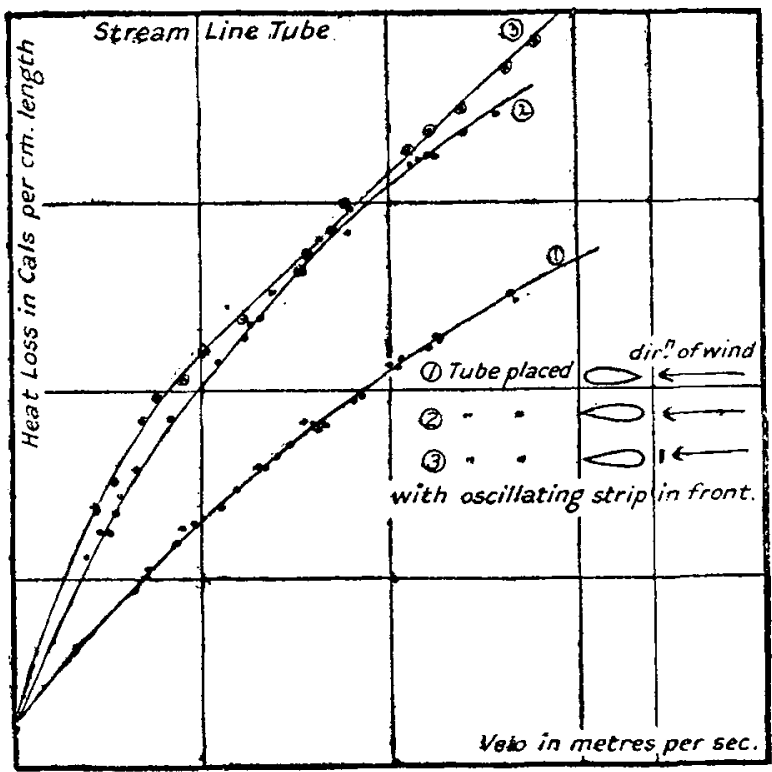

The values of $n$ obtained were :-

$$
\begin{aligned}
& \text { (1) } n=\cdot 67, \\
& \text { (2) } n=\cdot 62, \\
& \text { (3) } n=\cdot 61 \text {. }
\end{aligned}
$$

These results show that the heat lost from the stream-line tube is slightly greater than that lost from a circular tube of same total area, but much greater than from a circular tubo of the same width or same air resistance. This will be more clearly shown by the following comparative values.

(1) Heat-loss from stream-line tube at velocity 13 metres per sec. $=1735$ cals. per $\mathrm{cm}$. length.

(2) Heat-loss from cylinder of same diameter as the maximum thickness of stream-line tube at velocity 13 metres per sec. $=695$ cals. per cm. length.

(3) Heat-loss from a cylinder of the same total area $(7 \cdot 3 \mathrm{~cm}$. diam. approx. $)=1476$ cals. per $\mathrm{cm}$. length at velocity 13 metres per sec.

(4) Heat-loss from cylinder of the same air resistance as stream-line tube $\left(\frac{1}{7}\right.$ diam. $=\cdot 3 \mathrm{~cm}$.) at 13 metres per soc. $=233$ cals. per cm. length.

The curves in fig. 6 also show that the cooling is much greater when the stream-line tube is placed in position (2) 
130 Prof. W. B. Morton and Miss Harvey: Application of

than it is when placed in position (1), and with the oscillating strip the heat-loss is increased at low and very high velocities.

It is evident, then, that as a cooling apparatus a stream-line tube is in every respect more efficient than a circular one.

The above experiments were carried out in the Physical Laboratory of the University College of North Wales, and my best thanks are due to Professor E. Taylor Jones for placing the necessary apparatus at my disposal, and to Mr. W. E. Williams, B.Sc., A.F.Ae.S., for suggesting the subject and for giving most valuable help and advice.

XVIII. An application of Nomography to a case of Discontinuous Motion of a Liquid. By W. B. Morton, M.A., and Eleanor J. Harvey, M.A., Queen's University, Belfast*. $7 \mathrm{HE}$ problem of the impact, in two dimensions, of a jet of 1 frictionless liquid on a plane strip, when both jet and strip are of finite width, can be solved by the method of conformal representation. The solution was given by Prof. Love t. The equations which embody the result of the analysis are too complicated to admit of arithmetical calculation of special cases. It is the purpose of this note to point out how numerical results can be obtained by means of the graphical methods developed by M. d'Ocagne.

Fig. 1.

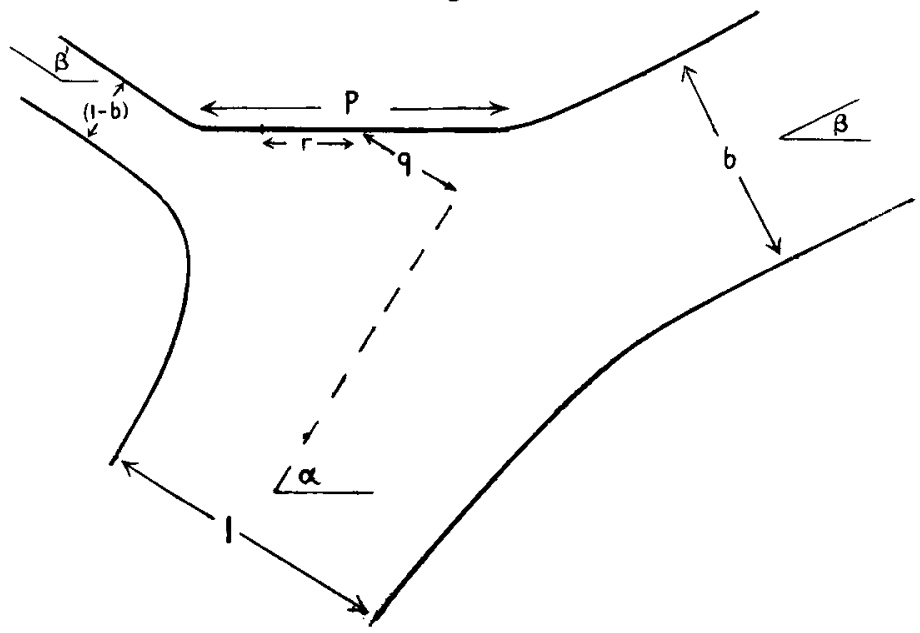

Taking the width of the undisturbed stream before incidence as unity (fig. 1), the data of the question are the * Communicated by the A uthors.

† Proc. Camb. Phil. Soc. vii. p. 175 (1891). 